\title{
Effect of surface layer freeze to soil-pile interaction
}

\author{
Takashi Sato ${ }^{1, *}$, Kazuo Konagai $^{2}$, Takaaki Ikeda $^{3}$, and Hiroaki Nishi ${ }^{1}$ \\ ${ }^{1}$ Civil Engineering Research Institute for Cold Region (CERI), 1-34-3 Hiragishi 1-jo, Toyohira-ku, \\ Sapporo, Hokkaido 062-8602, Japan \\ ${ }^{2}$ University of Tokyo, Principal Researcher, International Consortium on Landslides, 138-1 Tanaka- \\ Asukai cho, Sakyo-ku, Kyoto 606-8226, Japan \\ ${ }^{3}$ Nagaoka University of Technology, 1603-1, Kamitomioka, Nagaoka, Niigata 940-2188, Japan
}

\begin{abstract}
To assess earthquake resistance of new or existing structures and predict earthquake damage of structures, it is important to properly evaluate the response of the structure at the time of the earthquake. In cold regions however, where the ground can freeze in winter, the dynamic soilfoundation interaction can change with the change in the density and stiffness of the frozen side soil. This paper examines in a quantitative manner, the influence of freezing of ground on the dynamic soil grouped piles interaction., It is shown herein that the grouped piles in the frozen ground tend to follow the motion of the ground over a wider range of frequency. Furthermore, it is shown that even when the freezing depth is much thinner than the characteristic length of piles determined by the stiffness ratio of the ground and the group pile, the pile cap stiffness at the time of freezing becomes noticeably large. It is confirmed that the freezing of the ground can greatly affect the interaction between the ground and the piles.
\end{abstract}

\section{Introduction}

For examining seismic performances of existing and/or newly designed structures, it is important to properly evaluate their seismic responses to scenario earthquakes. Wotherspoon et al. experimentally and analytically revealed that the response of a structure in a frozen environment can differ from its response in summer time, thus indicating that the ground freezing can have a significant effect on the response of a structure [1-8].

The effect of both kinematic and inertia soil-foundation interactions have been intensively studied over decades by many researchers. However, no paper seems to have payed due attention to the effect of frozen ground surface to soil-foundation interactions. Toki K. et al. [9] compared seismic performances of two pile foundations embedded in a slightly different grounds; a semi-infinite uniform clay ground and the same clay ground with its cover soil replaced with sandy soil, and showed that the sandy cover soil can increase remarkably both the lateral and rocking impedances of the pile cap. Their result suggests that similar change of pile cap stiffness can happen in a frozen soil. This paper examines the effect of ground

\footnotetext{
*Corresponding author: taka4@ ceri.go.jp
} 
surface freezing on both kinematic and inertia soil-pile interactions, which can affect largely the performance of it superstructure.

\section{Method}

The ground is assumed to be a semi-infinite horizontally-layered elastic layer overlying a rigid bedrock with an inclusion of piles grouped together beneath a rigid pile cap (Fig. 1).

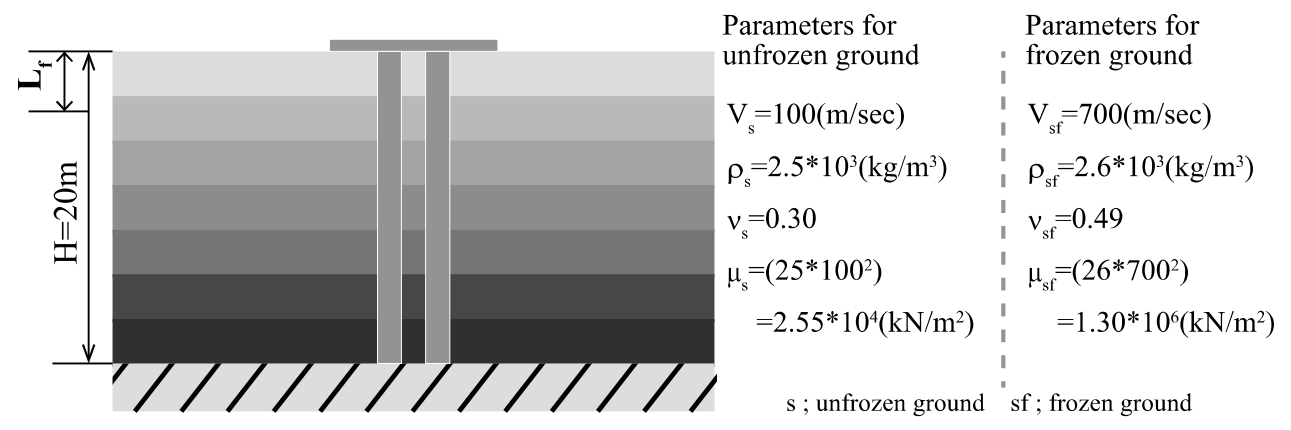

Fig. 1. Ground model and parameters of frozen and unfrozen ground.

To illustrate the effect of frozen soil in a simple manner, the side soil of the grouped pile foundation is assumed for now to be a uniform ground in summer time, while in winter, only the surface shallow soil changes its parameters (Fig. 1). To analyze the soil and the grouped piles interaction in a rigorous manner, a numerical program, TLEM (1.2) by Konagai K. [10], which is based upon a semi-analytical approach, Thin-Layered Method developed by Tajimi H. [11], is used herein. A unique feature of TLEM (1.2) is that a grouped pile foundation is replaced with a single upright beam (Konagai K. et al. [12]) of equivalent performance in sway and rocking movements. Neither Bernoulli-Euler beam nor Timoshenko beam can realize the similar performance of a grouped pile foundation (see more details in Konagai K. et al. [12]).

Both 4 and 9 steel piles are arranged in square at a regular interval of $s(s=2.5$ times as large the outer diameter of pile D) as shown in Fig. 2. Total 8 types of piles with different parameters shown in Table 1 are examined. In each case examined, the ground is sliced into total 80 horizontal thin slices of $0.5 \mathrm{~m}$ over the total depth of $20 \mathrm{~m}$.
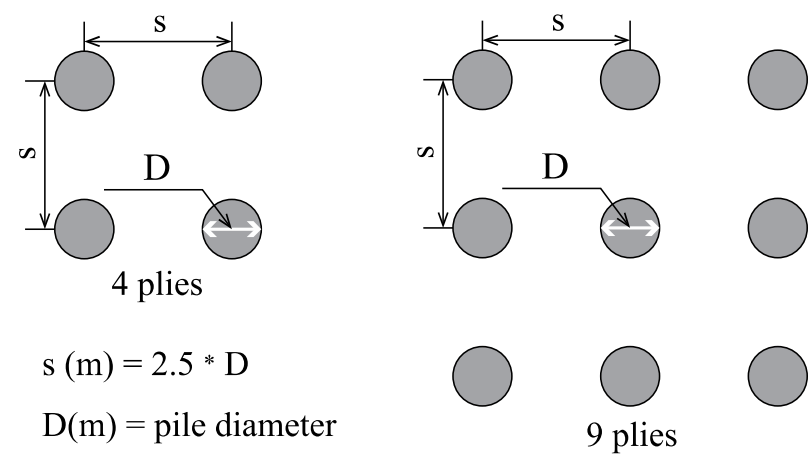

$$
\mathrm{D}(\mathrm{m})=\text { pile diameter }
$$
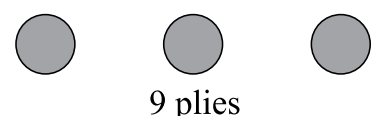

Fig. 2. Pile arrangement. 
Table 1. Systematic names of individual analyses and the types of steel pipe piles subjected to analysis.

\begin{tabular}{|l|l|l|l|l|l|l|}
\hline $\begin{array}{l}\text { Examined } \\
\text { pile types }\end{array}$ & $\begin{array}{l}\mathrm{E} \\
\left(\mathrm{kN} / \mathrm{m}^{2}\right)\end{array}$ & $\begin{array}{l}\text { Radius } \\
(\mathrm{m})\end{array}$ & $\begin{array}{l}\text { Wall } \\
\text { thickness }(\mathrm{m})\end{array}$ & $\begin{array}{l}\text { Unit } \\
\text { mass }(\mathrm{kg} / \mathrm{m})\end{array}$ & $\begin{array}{l}\text { Weight/unit } \\
\text { volume - }{ }_{-0}\left(\mathrm{t} / \mathrm{m}^{3}\right)\end{array}$ & $\begin{array}{l}\text { Second } \\
\text { moment } \\
\text { area I }\left(\mathrm{m}^{4}\right)\end{array}$ \\
\hline type01 & $2.08 \mathrm{E}+08$ & 0.20 & 0.009 & 86.8 & 7.848 & $2.114 \mathrm{E}-04$ \\
\hline type02 & $2.08 \mathrm{E}+08$ & 0.25 & 0.009 & 109 & 7.853 & $4.185 \mathrm{E}-04$ \\
\hline type03 & $2.08 \mathrm{E}+08$ & 0.30 & 0.009 & 131 & 7.840 & $7.297 \mathrm{E}-04$ \\
\hline type04 & $2.08 \mathrm{E}+08$ & 0.30 & 0.015 & 216 & 7.835 & $1.180 \mathrm{E}-03$ \\
\hline type05 & $2.08 \mathrm{E}+08$ & 0.40 & 0.009 & 176 & 7.871 & $1.749 \mathrm{E}-03$ \\
\hline type06 & $2.08 \mathrm{E}+08$ & 0.50 & 0.012 & 292 & 7.839 & $4.545 \mathrm{E}-03$ \\
\hline type07 & $2.08 \mathrm{E}+08$ & 0.60 & 0.014 & 409 & 7.841 & $9.173 \mathrm{E}-03$ \\
\hline type08 & $2.08 \mathrm{E}+08$ & 0.60 & 0.022 & 639 & 7.848 & $1.413 \mathrm{E}-02$ \\
\hline
\end{tabular}

\section{Results and discussions}

Kinematic interaction effect is often shown in the frequency domain as the transmissibility of free-field ground motion to the pile foundation. In many cases, the transmissibility is close to one for translational movement because piles are normally very flexible in sway movement and they easily follow the motion of their side soils. But when the length of shear wave, which travels predominantly in vertical direction through the ground, becomes shorter, the piles become relatively stiff such that they hardly follow the ground movement. The stiffness of piles in their flexural movement is largely affected by the stiffness ratio between the side soil and piles. When a group of flexible piles is subjected to a lateral load on its pile cap, only the top part of the piles practically above a specific depth $L_{a}$ will be deformed. This $L_{a}$ is referred to as the active pile length and is proportional to:

$$
L_{0}=\sqrt[4]{E I / G}
$$

where $E I$ is the bending stiffness of the pile group (equivalent upright beam). Therefore, transfer functions for all examined cases are shown in Fig. 3 as functions of non-dimensional frequency $\omega L_{0} / v_{s}$ where $\omega(=2 \pi f)=$ circular frequency and $v_{s}=$ shear wave velocity through side soil beneath the frozen ground surface. The non-dimensional frequency can be readily interpreted as the ratio of $L_{0}$ to the shear wave length $\left(v_{s} / f\right)$ divided by $2 \pi$.

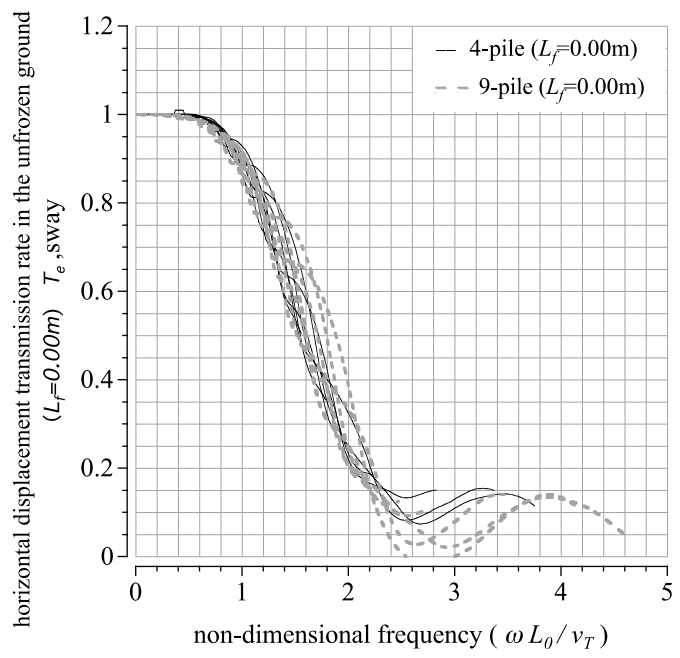

Fig. 3. Interaction between piles and the foundation ground (unfrozen ground). 


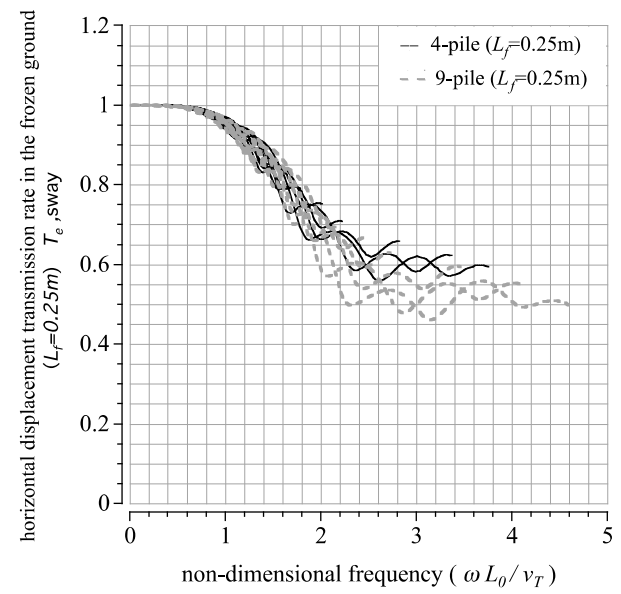

(a) Freezing depth: $0.25 \mathrm{~m}$

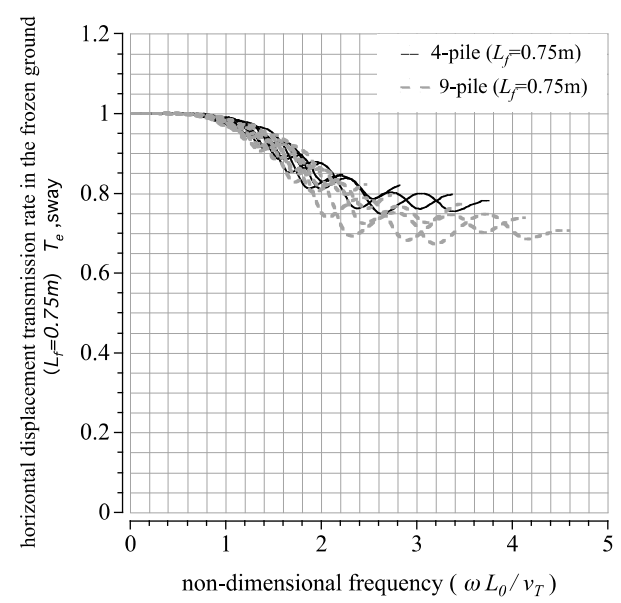

(c) Freezing depth: $0.75 \mathrm{~m}$

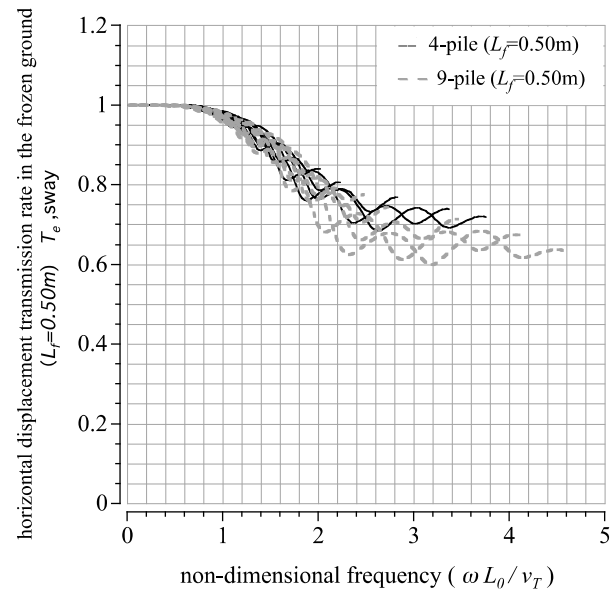

(b) Freezing depth: $0.50 \mathrm{~m}$

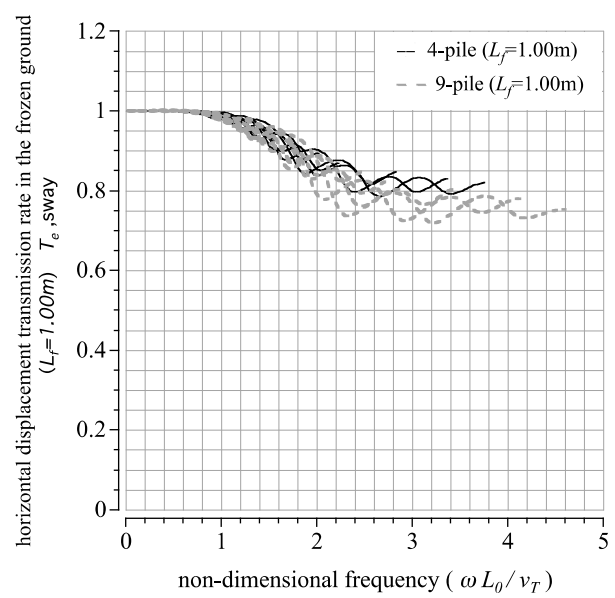

(d) Freezing depth: $1.00 \mathrm{~m}$

Fig. 4. Interaction between piles and the foundation ground in relation to different freezing depths.

All examined transfer functions in each of Figs. 3 and 4(a) to 4(d) for summer and winter times respectively overlap one another along a unique curve for translational motion. This clearly indicates that the active pile length $L_{a}$, which is proportional to $L_{0}$, is an important key parameter governing the kinematic soil-pile interaction. The effect of frozen surface soil is very clear when these figures are compared. As the frozen surface soil layer becomes thicker (from Fig. 4(a) to 4(d)), the transmissibility of free-field ground motion to the pile cap motion, which is shown by unique curves in each of Figs. 4(a) to 4(d), gradually converges on 1 over a wide range of non-dimensional frequency $\omega L_{0} / v_{T}$. Fig. 5 makes this trend more visible with the all unique curves in all Fig. 3, Figs. 4(a), (b), (c) and (b) drawn on the same figure frame.

Fig. 6 shows the pile cap stiffnesses $k_{x x}$ in summer (Fig. 6(a)) and winter (Fig. 6(b)) times for sway motions of $2 \times 2$ and $3 \times 3$ steel pile groups of Type 4 in Table 1 plotted as functions of frequency. Downward dips in these plots of both real and imaginary parts of $k_{x x}$ occur at essentially the resonance frequencies of the soil stratum for vertical shear wave propagation. 


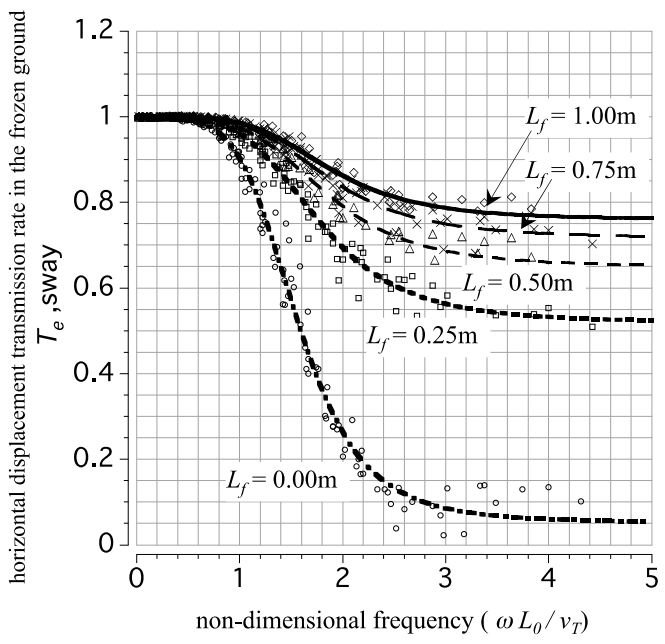

Fig. 5. Interaction between piles and the foundation ground.

As a whole however, every real part of the pile cap stiffnesses is almost constant over the important frequency range for the earthquake engineering practice, whereas its imaginary part representing the wave radiation damping effect of a soil-pile group system shows a general upward trend to the right. These features of the curves indicate that the pile cap stiffness $k_{x x}$ in sway motions can be approximated by a parallel connection of a spring $K_{0}$ and a damper $C_{0}$ whose dynamic stiffness in the domain of circular frequency $\omega$ can be given by:

$$
k_{x x} \cong K_{0}+i \omega C_{0}
$$

The average values of $K_{0}$ for all examined cases were obtained over the frequency range of 0.1 to $5.0 \mathrm{~Hz}$, and the rates of pile-cap stiffness change from summer time to winter time are shown as functions of the ratio of frozen depth $L_{f}$ to $L_{0}$ defined by Equation (1). All cases examined are found falling upon a unique curve showing an upward trend to the right as shown in Fig. 7. Thus $L_{0}$ is found to be an important parameter to describe the important effect of frozen surface soils on the soil-grouped piles interaction.

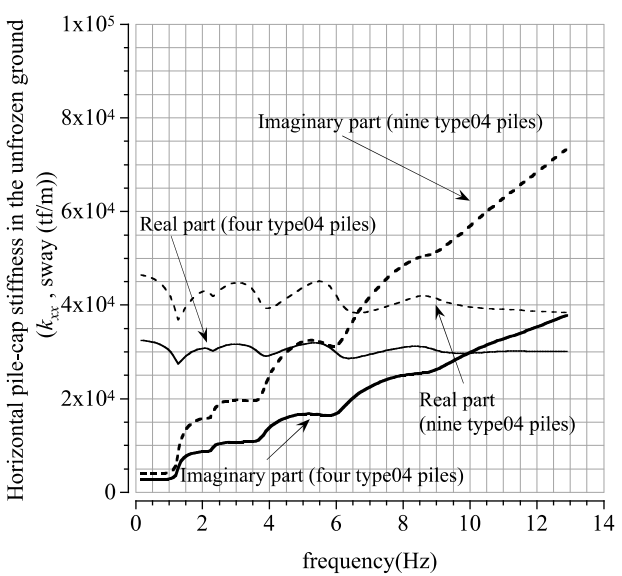

(a) Unfrozen ground

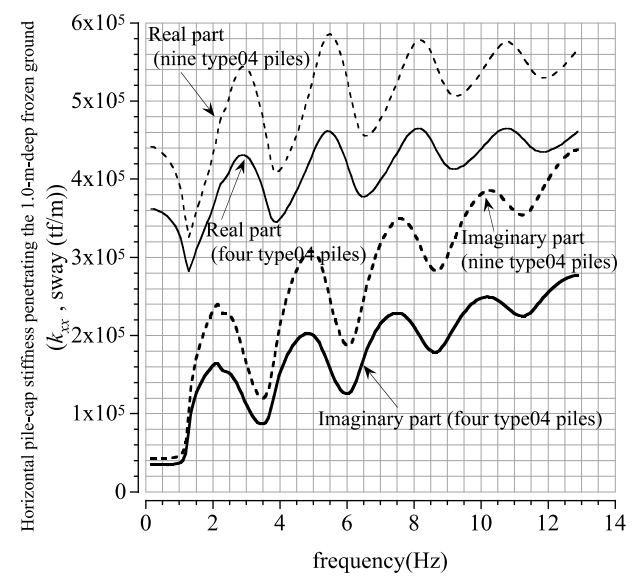

(b) 1.0-m-deep frozen ground

Fig. 6. Horizontal stiffness $\left(k_{x x}\right)$ at the top of type04 piles. 


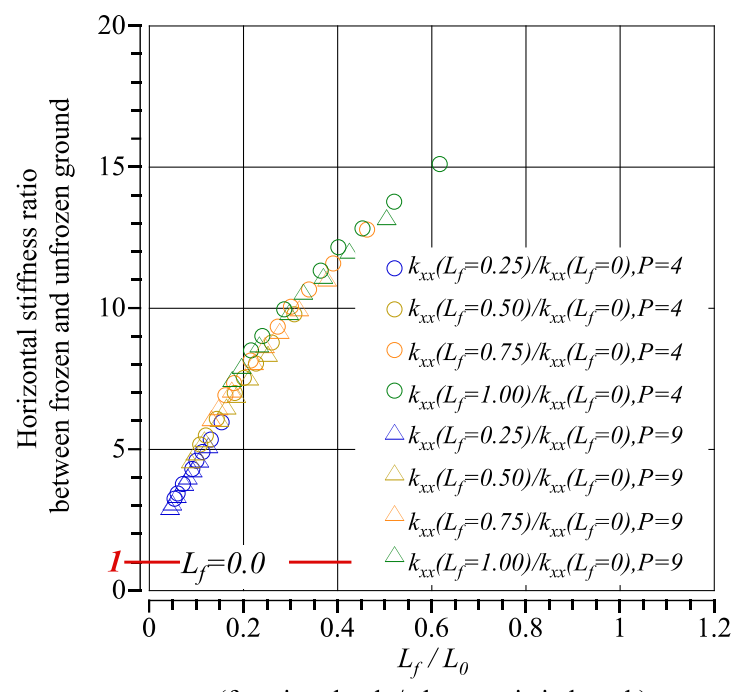

(freezing depth / characteristic length)

Fig. 7. Change in horizontal stiffness ratio in relation to freezing depth adjusted by characteristic length.

\section{Conclusions}

The effect of a frozen surface soil layer on the soil-grouped piles interaction were examined in a quantitative manner. The foundation of piles grouped together beneath a pile cap is assumed to be embedded in a homogeneous soil stratum with an infinite extent in the horizontal direction, which stratum overlies a rigid bedrock. This study has shown that the grouped piles in the frozen ground tend to follow the motion of the ground over a wider range of frequency. It was also shown that even when the freezing depth $L_{f}$ is thin, the pile cap stiffness at the time of freezing can become noticeably large. The obtained results suggested that the active pile length $L_{a}$, which is proportional to $L_{0}(=\sqrt[4]{E I})$, is an important key parameter to describe uniquely the effect of frozen surface soil of the thickness $L_{f}$ on the pile cap stiffness $k_{x x}$ in sway motion. The kinematic interaction between the frozen ground and grouped piles in the frequency domain was also found to be uniquely described by using nondimensional frequency $\omega L_{0} / v_{s}$.

Further extensive studies are necessary for the frozen soil effect on the pile cap stiffness in rocking motion, and will appear in future publications.

\section{References}

1. H. Vaziri, Y.C. Han, Canadian Geotechnical Jnl. 28, 708-718 (1991)

2. M.T. Suleiman, S. Sritharan, D.J. White, ASCE Jnl. of Structural Engineering 132-11, 1745-1754 (2006)

3. S. Sritharan, M.T. Suleiman, D.J. White, Earthquake Spectra 23, 199-222 (2007)

4. Z. Yang, U. Dutta, D. Zhu, ASCE Jnl. of Cold Regions Engineering 21, 108-120 (2007)

5. F. Xiong, Z. Yang, Cold Regions Sci-ence and Technology 54, 44-53 (2008)

6. L.M. Wotherspoon, S. Sritharan, M.J. Pender, ASCE Jnl. of Bridge Engineering 15-5, 473-481 (2010) 
7. L.M. Wotherspoon, S. Sritharan, M.J. Pender, Engineering Structures 32, 933-943 (2010)

8. L.M. Wotherspoon, S. Sritharan, M.J. Pender, Proceedings of 10th U.S. National Conference on Earthquake Engineering (2014)

9. K. Toki, J. Kiyono, Y. Ono, A. Furukawa, Journal of JSCE 710, 235-245 (2002)

10. K. Konagai, Guide to "TLEM1.2”(SOLVER in BASPIA), program manual (Konagai, Univ. of Tokyo, 1999)

11. H. Tajimi, Y. Shimomura, Trans. Arch. Inst. Japan 243, 41-51 (1976)

12. K. Konagai, R. Ahsan, D. Murayama, Journal of Earthquake Engineering 4(3), 355-376 (2000) 